Esta revista forma parte del acervo de la Biblioteca Jurídica Virtual del Instituto de Investigaciones Jurídicas de la UNAM www.juridicas.unam.mx

\title{
Candidaturas independientes. Experiencia Zacatecas
}

\section{Leticia Catalina Soto Acosta*}

\section{Sumario:}

\author{
I. Introducción \\ II. Fundamento constitucional y legal \\ III. Experiencia Zacatecas \\ IV. Conclusiones \\ V. Fuentes consultadas
}

* Consejera presidenta del Instituto Electoral del Estado de Zacatecas. Doctora en Derecho por el Instituto Internacional del Derecho y del Estado de la Universidad Autónoma de Zacatecas. 


\section{Introducción}

El sistema electoral mexicano se ha abierto a una nueva forma de participación política y búsqueda del ejercicio del poder público. En un sistema de partidos, sin las reformas estructurales necesarias y como una respuesta a la necesidad de garantizar el ejercicio pleno de los derechos político electorales, surgen los primeros ejercicios de las candidaturas independientes.

A partir de la reforma constitucional de junio de 2011 en que se han colocado en el centro de nuestra Constitución general los derechos fundamentales y la obligación de las autoridades de garantizar su ejercicio, se trazó la ruta para una evolución en la forma de participación política.

De igual manera, en la reforma se reconoció que las normas relativas a derechos humanos se interpretarán de conformidad con la Constitución y con los tratados internacionales de los que México sea parte, favoreciendo en todo momento a las personas la protección más amplia bajo el principio pro homine. Se determinó además, que todas las autoridades tienen la obligación de promover, respetar, proteger y garantizar los derechos humanos de conformidad con los principios de universalidad, independencia, indivisibilidad y progresividad.

Ante este reconocimiento de la protección de los derechos político electorales, arribó la reforma al artículo 35 de la Constitución Política de los Estados Unidos Mexicanos, de agosto de 2012 que finalizó con el monopolio de los partidos políticos de solicitar el registro de candidatos ante la autoridad electoral y amplió el derecho a los ciudadanos que lo soliciten de manera independiente y que cumplan con los requisitos, condiciones y términos que determine la legislación. El Decreto en sus artículos transitorios segundo y tercero estableció la obligación de los Congresos locales y la Asamblea de ajustar sus disposiciones legales a las nuevas disposiciones y señaló el plazo de un año a efecto de que el Congreso de la Unión expidiera las normas secundarias para regular este derecho, plazo que por cierto ha vencido.

Sin embargo, la reforma no tocó los artículos 41 y 116 de la propia Constitución para generar una armonización entre un sistema electoral basado en los partidos políticos y la introducción de las candidaturas independientes. 
Por tanto, este artículo tiene como finalidad presentar la experiencia de Zacatecas en la puesta en operación de las candidaturas independientes y la enseñanza adquirida, lo cual no debe soslayarse para abordar una adecuada regulación en las entidades federativas y en la propia federación.

\section{Fundamento constitucional y legal}

El 9 de agosto de 2012, se publicó en el Diario Oficial de la Federación, el Decreto por el que se reformaron y adicionaron diversas disposiciones de la Constitución Política de los Estados Unidos Mexicanos, entre las cuales se incluyó la reforma al artículo 35 y se estableció que el derecho de solicitar el registro de candidaturas ante la autoridad electoral corresponde a los partidos políticos y a los ciudadanos que soliciten su registro de manera independiente y cumplan con los requisitos, condiciones y términos que determine la legislación.

El 6 de octubre de 2012, se publicó en el Periódico Oficial, Órgano de Gobierno del Estado de Zacatecas, el Decreto 426, mediante el cual se emitió la nueva Ley Electoral del Estado de Zacatecas y se abrogó la Ley Electoral de Zacatecas de 2013.

Cabe destacar que el derecho de participar a través de una candidatura independiente no fue elevado a rango constitucional y sólo se contempló en la nueva Ley Electoral del Estado de Zacatecas, en las disposiciones de tres artículos.

\section{Acciones de inconstitucionalidad 57/2012 y acumuladas}

El 5 de noviembre de 2012, la procuradora general de la República, el partido político Movimiento Ciudadano, el Partido del Trabajo, yel Partido de la Revolución Democrática, promovieron acciones de inconstitucionalidad mediante las que solicitaron la invalidez de algunos artículos de la Ley Electoral, ${ }^{1}$ entre los que se encontraban los artículos 17,18 y 19 por considerar que regulaban de manera deficiente

${ }^{1}$ Ley Electoral del Estado de Zacatecas. 
las candidaturas independientes y violaban, entre otros, el principio de certeza electoral.

La Suprema Corte de Justicia de la Nación, determinó desestimar las acciones de inconstitucionalidad respecto de los artículos 17, 18 y 19 de la Ley Electoral del Estado de Zacatecas y de conformidad a las intervenciones que constan en la versión estenográfica de la sesión del 10 de diciembre de 2012, se sostuvo que la reglamentación realizada por la Legislatura del Estado en materia de candidaturas independientes fue deficiente, por lo que el Instituto Electoral tendría que regular los aspectos que no fueron abordados en la propia Ley Electoral.

Por tanto, se enfrentó el inicio del proceso electoral local en enero de 2013 con una regulación deficiente de las candidaturas independientes, que no se encontraban armonizadas a todo el sistema electoral y se enfrentaron retos importantes en temas como precampañas o derecho a proselitismo para obtener el apoyo ciudadano, acceso a radio y televisión, derecho al listado nominal y muchos otros tópicos que se intentarán abordar en esta colaboración.

\section{Experiencia Zacatecas}

Las candidaturas independientes fueron puestas en marcha en el proceso electoral de 2013, en el que se renovaron el Poder Legislativo y los Ayuntamientos de los cincuenta y ocho municipios que conforman la entidad.

Participaron nueve candidatos independientes en la contienda electoral para los Ayuntamientos de Cañitas de Felipe Pescador, General Enrique Estrada, Mazapil, Pinos, dos candidatos independientes en Sombrerete, Villa de Cos, Villa García y Zacatecas.

Uno de ellos, Raúl de Luna Tovar actualmente es presidente municipal de General Enrique Estrada, Zacatecas al haber obtenido una votación del $43.03 \%{ }^{2}$ sobre el resto de los contendientes.

2 Página web del Instituto Electoral del Estado de Zacatecas: www.ieez.org.mx 
Esta revista forma parte del acervo de la Biblioteca Jurídica Virtual del Instituto de Investigaciones Jurídicas de la UNAM

Resultados electorales del municipio General Enrique Estrada, Zacatecas $^{3}$

\begin{tabular}{|c|c|c|c|c|c|c|c|c|c|c|}
\hline & (PAD) & $\mathrm{P}^{\mathrm{B}}$ & $\begin{array}{l}\text { 㴓 } \\
\text { PRD }\end{array}$ & $P^{\star}$ & $\frac{5}{5}$ & MoviniENT & $\overbrace{\text { alianzeta }}$ & & $\begin{array}{l}\text { Votos } \\
\text { nulos }\end{array}$ & Total \\
\hline $\begin{array}{c}\text { Gral. } \\
\text { Enrique } \\
\text { Estrada }\end{array}$ & 647 & 432 & 463 & 115 & 59 & 2 & 16 & 1377 & 89 & 3200 \\
\hline
\end{tabular}

Partimos del principio de que los candidatos y candidatas independientes son actores políticos, participantes que se deben insertar en el proceso electoral de manera armónica, que tienen derechos y obligaciones, que hacen política, que buscan el apoyo de la ciudadanía necesario para la participación formal, que su actividad antes de la candidatura tiene como objetivo lograr el respaldo necesario para presentarse formalmente al electorado, y que, como candidatos formales, han de participar en condiciones mínimas de equidad.

En ese sentido, para establecer las condiciones necesarias para la participación del candidato independiente, y generar las condiciones mínimas de equidad en la contienda y en atención a las facultades extraordinarias otorgadas por la Suprema Corte de Justicia de la Nación que determinó que la regulación insuficiente debería ser integrada por el órgano electoral, el Instituto Electoral del Estado de Zacatecas a través de su Consejo General aprobó el Reglamento de Candidaturas Independientes que regula lo dispuesto en los artículos 17, 18 y 19 de la Ley Electoral del Estado de Zacatecas, con los siguientes apartados:

- Los derechos, obligaciones y prohibiciones político-electorales de las ciudadanas y los ciudadanos que se postulen a cargos de elección popular de manera independiente.

- El registro de candidaturas independientes a los cargos de elección popular.

3 Acuerdo ACG-IEEZ-090/IV/2013 del Consejo General del Instituto Electoral del Estado de Zacatecas, por el que se aprueba el cómputo estatal de la elección de regidores por el principio de representación proporcional, se declara su validez y se asignan a los partidos políticos: Acción Nacional, Revolucionario Institucional, de la Revolución Democrática, del Trabajo, Verde Ecologista de México, Movimiento Ciudadano y Nueva Alianza, las regidurías que por este principio les corresponden de acuerdo a la votación obtenida por cada uno de ellos, en el proceso electoral de 2013 y se expiden las constancias de asignación respectivas. 
Esta revista forma parte del acervo de la Biblioteca Jurídica Virtual del Instituto de Investigaciones Jurídicas de la UNAM

- Los requisitos de elegibilidad.

- El financiamiento de las candidaturas independientes (que de conformidad con la ley, sólo fue privado), la fiscalización del origen y destino de sus recursos y el procedimiento de recuperación de éstos en caso de obtener el triunfo en la elección.

- El acceso de las candidatas y los candidatos independientes a radio, televisión y a los medios de comunicación impresos.

- Las condiciones de equidad en la contienda electoral.

Se destaca que el Reglamento estableció la obligación de los candidatos independientes de respetar las reglas de paridad entre los géneros, en el momento del registro.

\section{Emisión de la convocatoria}

Para que los aspirantes a la candidatura independiente conocieran las bases de participación, el Consejo General del Instituto Electoral aprobó la expedición de las Convocatorias dirigidas a las ciudadanas y a los ciudadanos que de manera independiente desearan participar en la elección ordinaria para renovar los Ayuntamientos de los 58 municipios del estado, por el principio de mayoría relativa y la Honorable Legislatura del Estado para el periodo 2013-2016. ${ }^{4}$

\section{Escrito de intención y apoyo ciudadano}

Con el objeto de que se generara certeza respecto de quiénes realizarían las actividades para la obtención del apoyo ciudadano, para empa-

4 Acuerdo ACG-IEEZ-025/IV/2013 del Consejo General por el que se aprueba la modificación, en su parte conducente, de la Convocatoria dirigida a las ciudadanas y a los ciudadanos que de manera independiente deseen participar en la elección ordinaria para renovar los Ayuntamientos de los 58 municipios del estado de Zacatecas, por el principio de mayoría relativa, para el periodo constitucional 2013-2016 y de la Convocatoria dirigida a las ciudadanas y a los ciudadanos que de manera independiente deseen participar en la elección ordinaria para renovar la Honorable Legislatura del Estado de Zacatecas, para el periodo constitucional 2013-2016; con base en la sentencia dictada por la Sala Superior del Tribunal Electoral del Poder Judicial de la Federación, en el expediente SUPJDC-41-2013 y acumulados. 
tar el calendario entre las precampañas y el apoyo ciudadano, y para dar seguridad al independiente respecto de que sus actos de obtención del apoyo no serían considerados actos de precampaña, se estableció como requisito previo al registro la presentación de un "escrito de intención” de participación en calidad de independiente.

El mencionado requisito fue materia de impugnación así como los consistentes en que la relación de apoyo ciudadano debería hacerse constar mediante fe de hechos notarial y que la copia simple de las credenciales de elector de los ciudadanos que apoyaran la candidatura independiente, deberían estar cotejadas por fedatario público, contenidos en la ley electoral. ${ }^{5}$

La Sala Superior del Tribunal Electoral del Poder Judicial de la Federación al resolver el Juicio para la Protección de los Derechos PolíticoElectorales del Ciudadano SUP-JDC-41/2013 determinó, en ejercicio de la facultad de control de la constitucionalidad concreto, la inaplicación de la disposición que establecía la actuación notarial y la expulsión del Reglamento de Candidaturas Independientes lo relativo al escrito de intención.

Derivado de la resolución anterior, el Tribunal Electoral del Poder Judicial de la Federación emitió la tesis relevante VIII/2013 cuyo rubro es: CANDIDATURAS INDEPENDIENTES. ES INCONSTITUCIONAL EXIGIR ESCRITO DE INTENCIÓN PARA EL REGISTRO (LEGISLACIÓN DE ZACATECAS).

Cabe destacar que el propio actor del medio de impugnación presentó su escrito de intención ante la autoridad administrativa electoral en el plazo establecido.

Sin embargo, se trata de un asunto de fondo. Aún más, cuando en las recientes modificaciones legales algunas legislaturas están incluyendo el escrito de intención y empatando esta fecha con el inicio de precampañas, tal como se contempló en nuestro reglamento, situación que fue resuelta por la Sala Superior del Tribunal Electoral del Poder Judicial de la Federación en el caso de Zacatecas.

Y resulta oportuno destacar que, en nuestro caso, la Sala Superior resolvió en el sentido de que si no estaba contemplado el anuncio en la ley, resultaba inconstitucional; se advierte que no se ha realizado un

5 Artículo 18, numeral 1, fracciones II y III de la Ley Electoral del Estado de Zacatecas. 
test de proporcionalidad para determinar si solicitar tal escrito resulta innecesario, no idóneo o desproporcional.

De ahí el análisis que debe realizarse respecto a la presentación de dicho escrito, pues lejos de ser un intento para inhibir la participación, resulta indispensable para empatar el juego político. Por lo tanto, surgen las preguntas respecto de si se trata de un requisito contrario a la Constitución Política de los Estados Unidos Mexicanos y a los tratados internacionales, al constituir un obstáculo al ejercicio a un derecho fundamental o si, por el contrario se genera certeza respecto de quienes se encuentran realizando diversas actividades para obtener el apoyo ciudadano y no ser posibles sujetos de la imposición de alguna sanción por considerarse actos anticipados de precampaña derivado de la actividad desplegada.

\section{Registro preliminar y plataformas electorales}

De conformidad con las disposiciones legales y complementarias, diez días antes del inicio del periodo de registro, quienes aspiraron a participar como candidatos independientes a cargos de elección popular presentaron su solicitud de registro preliminar, a la que adjuntaron el apoyo ciudadano y, entre otros documentos, su plataforma electoral.

Se recibieron doce solicitudes de registro preliminar, que se presentaron por parte de los aspirantes a la candidatura independiente para obtener la constancia de registro preliminar, diez cumplieron con los requisitos legales y reglamentarios.

\section{Fechas de presentación de plataformas electorales de los aspirantes a candidatos independientes}

\begin{tabular}{|c|c|c|}
\hline $\begin{array}{c}\text { Logo del } \\
\text { candidato } \\
\text { independiente }\end{array}$ & $\begin{array}{c}\text { Fecha de presentación } \\
\text { de la plataforma } \\
\text { electoral }\end{array}$ & Documento \\
\hline & 25 de marzo de 2013 & "Plataforma Política - Raúl de Luna Tovar-" \\
\hline
\end{tabular}


Esta revista forma parte del acervo de la Biblioteca Jurídica Virtual del Instituto de Investigaciones Jurídicas de la UNAM

\begin{tabular}{|c|c|c|}
\hline $\begin{array}{l}\text { Logo del } \\
\text { Candidato } \\
\text { Independiente: }\end{array}$ & $\begin{array}{c}\text { Fecha de presentación } \\
\text { de la Plataforma } \\
\text { Electoral }\end{array}$ & Documento: \\
\hline & 5 de abril de 2013 & $\begin{array}{c}\text { "Plataforma Electoral. Por una nueva forma } \\
\text { de gobierno que responda a los desafíos del } \\
\text { siglo XXI" }\end{array}$ \\
\hline & 5 de abril de 2013 & $\begin{array}{c}\text { "Plataforma Electoral. Por una nueva forma } \\
\text { de gobierno que responda a los desafíos del } \\
\text { siglo XXI" }\end{array}$ \\
\hline & 6 de abril de 2013 & $\begin{array}{c}\text { "La Plataforma Electoral Ing. Rogelio } \\
\text { Cárdenas Hernández" }\end{array}$ \\
\hline & 6 de abril de 2013 & $\begin{array}{c}\text { "La Plataforma Electoral para el Municipio } \\
\text { de Mazapil, Zacatecas" }\end{array}$ \\
\hline & 6 de abril de 2013 & $\begin{array}{c}\text { "Plataforma Electoral. Por una nueva forma } \\
\text { de gobierno que responda a los desafíos del } \\
\text { siglo XXI" }\end{array}$ \\
\hline & 6 de abril de 2013 & $\begin{array}{c}\text { "Propuestas a Desarrollar MVZ. Miguel } \\
\text { Morales García" }\end{array}$ \\
\hline $\begin{array}{l}\text { MAVY } \\
\text { MEJ } \\
\text { MOEFEN }\end{array}$ & 6 de abril de 2013 & $\begin{array}{c}\text { "Un gobierno independiente para un mejor } \\
\text { Guadalupe" }\end{array}$ \\
\hline & 6 de abril de 2013 & "La Plataforma Electoral" \\
\hline & 6 de abril de 2013 & $\begin{array}{l}\text { "La Plataforma Político Electoral del periodo } \\
\text { 2013-2016" }\end{array}$ \\
\hline
\end{tabular}

Del contenido de las plataformas electorales se destaca que contemplan los ejes centrales: seguridad pública, desarrollo económico, desarrollo rural, salud y deporte. Asimismo, tres plataformas tienen el mismo contenido.

\section{Apoyo ciudadano}

Quienes aspiraron a una candidatura independiente, que en todos los casos fue para Ayuntamiento, contaron con el apoyo ciudadano de un número determinado de ciudadanos inscritos en el padrón electoral con corte al 31 de diciembre de 2012.

- Para diputados de mayoría relativa, la relación de apoyo debería contener el 15\% del padrón electoral correspondiente al distrito uninominal con corte a diciembre del año anterior. 
Esta revista forma parte del acervo de la Biblioteca Jurídica Virtual del Instituto de Investigaciones Jurídicas de la UNAM www.juridicas.unam.mx

DOI: http://dx.doi.org/10.22201/iij.24487910e.2014.5.10058

http://biblio.juridicas.unam.mx

\begin{tabular}{|c|c|c|c|}
\hline Distritos & Padrón & $\begin{array}{l}\text { Porcentaje } \\
\text { requerido }\end{array}$ & $\begin{array}{l}\text { Número de firmas } \\
\text { requeridas de conformidad } \\
\text { con el corte del padrón } \\
\text { electoral al } 31 \text { de diciembre } \\
\text { de } 2012 \text {. }\end{array}$ \\
\hline ZACATECASI & 49301 & \multirow{18}{*}{$15 \%$} & 7396 \\
\hline ZACATECAS $\|$ & 57353 & & 8603 \\
\hline CALERA III & 60469 & & 9071 \\
\hline GUADALUPE IV & 59132 & & 8870 \\
\hline GUADALUPE V & 49273 & & 7391 \\
\hline OJOCALIENTE VI & 77005 & & 11551 \\
\hline JEREZ VII & 86364 & & 12955 \\
\hline FRESNILLOVIII & 75428 & & 11315 \\
\hline LORETOIX & 77579 & & 11637 \\
\hline VILLANUEVAX & 72050 & & 10808 \\
\hline FRESNILLOXI & 87060 & & 13059 \\
\hline RIO GRANDE XII & 76453 & & 11468 \\
\hline PINOS XIII & 64382 & & 9658 \\
\hline JUCHIPILA XIV & 60151 & & 9023 \\
\hline $\begin{array}{c}\text { TLALTENANGO DE SANCHEZ ROMAN } \\
\text { XV }\end{array}$ & 69551 & & 10433 \\
\hline SOMBRERETE XVI & 65761 & & 9865 \\
\hline JUAN ALDAMA XVII & 54026 & & 8104 \\
\hline CONCEPCION DEL ORO XVIII & 54523 & & 8179 \\
\hline
\end{tabular}

\section{Porcentaje y número de firmas requeridas para la elección de diputados}

Para la elección de planillas de ayuntamientos la relación de apoyo ciudadano debería contener el 15\%, 10\%, 8\% y 5\% del padrón electoral correspondiente al municipio que se trate con corte a diciembre del año anterior. 
Esta revista forma parte del acervo de la Biblioteca Jurídica Virtual del Instituto de Investigaciones Jurídicas de la UNAM www.juridicas.unam.mx

\section{Porcentaje y número de firmas requeridas para la elección de Ayuntamientos}

\begin{tabular}{|c|c|c|c|c|}
\hline Población & Municipios & $\begin{array}{c}\text { Porcentaje } \\
\text { requerido }\end{array}$ & $\begin{array}{l}\text { Padrón } \\
\text { Electoral }\end{array}$ & $\begin{array}{l}\text { Número de firmas } \\
\text { requeridas de } \\
\text { conformidad con } \\
\text { el corte del padrón } \\
\text { electoral al } 31 \text { de } \\
\text { diciembre de } 2012\end{array}$ \\
\hline \multirow{37}{*}{$\begin{array}{c}\text { En } \\
\text { municipios } \\
\text { con una } \\
\text { población } \\
\text { de hasta } \\
15000 \\
\text { electores }\end{array}$} & Apozol & \multirow{37}{*}{$15 \%$} & 6576 & 987 \\
\hline & Apulco & & 4719 & 708 \\
\hline & Atolinga & & 3261 & 490 \\
\hline & Benito Juarez & & 4014 & 603 \\
\hline & $\begin{array}{c}\text { Cañitas De Felipe } \\
\text { Pescador }\end{array}$ & & 6554 & 984 \\
\hline & Chalchihuites & & 10228 & 1535 \\
\hline & Concepcion Del Oro & & 9753 & 1463 \\
\hline & Cuauhtemoc & & 9014 & 1353 \\
\hline & Genaro Codina & & 6222 & 934 \\
\hline & General Enrique Estrada & & 4965 & 745 \\
\hline & Huanusco & & 4723 & 709 \\
\hline & Jimenez Del Teul & & 3832 & 575 \\
\hline & Juchipila & & 12843 & 1927 \\
\hline & Luis Moya & & 10063 & 1510 \\
\hline & Mazapil & & 14289 & 2144 \\
\hline & Melchor Ocampo & & 2375 & 357 \\
\hline & Mezquital Del Oro & & 2816 & 423 \\
\hline & Momax & & 2822 & 424 \\
\hline & Monte Escobedo & & 9112 & 1367 \\
\hline & Morelos & & 8762 & 1315 \\
\hline & Moyahua De Estrada & & 5623 & 844 \\
\hline & Noria De Angeles & & 11369 & 1706 \\
\hline & Panuco & & 11803 & 1771 \\
\hline & $\begin{array}{c}\text { Plateado De Joaquin } \\
\text { Amaro, El }\end{array}$ & & 2098 & 315 \\
\hline & Salvador, El & & 2325 & 349 \\
\hline & Santa Maria De La Paz & & 2761 & 415 \\
\hline & Susticacan & & 1404 & 211 \\
\hline & Tabasco & & 13747 & 2063 \\
\hline & Tepechitlan & & 8304 & 1246 \\
\hline & Tepetongo & & 7869 & 1181 \\
\hline & Teul De Gonzalez Ortega & & 5124 & 769 \\
\hline & Trancoso & & 12027 & 1805 \\
\hline & $\begin{array}{c}\text { Trinidad Garcia De La } \\
\text { Cadena }\end{array}$ & & 3303 & 496 \\
\hline & Vetagrande & & 7364 & 1105 \\
\hline & Villa Garcia & & 12573 & 1886 \\
\hline & Villa Gonzalez Ortega & & 10579 & 1587 \\
\hline & Villa Hidalgo & & 13605 & 2041 \\
\hline
\end{tabular}


Esta revista forma parte del acervo de la Biblioteca Jurídica Virtual del Instituto de Investigaciones Jurídicas de la UNAM

\begin{tabular}{|c|c|c|c|c|}
\hline Población & Municipios & $\begin{array}{l}\text { Porcentaje } \\
\text { requerido }\end{array}$ & $\begin{array}{l}\text { Padrón } \\
\text { Electoral }\end{array}$ & $\begin{array}{l}\text { Número de firmas } \\
\text { requeridas de } \\
\text { conformidad con } \\
\text { el corte del padrón } \\
\text { electoral al } 31 \text { de } \\
\text { diciembre de } 2012\end{array}$ \\
\hline \multirow{11}{*}{$\begin{array}{c}\text { En } \\
\text { municipios } \\
\text { con una } \\
\text { población } \\
\text { de } 15,001 \\
\text { hasta } 30,000 \\
\text { electores }\end{array}$} & Calera & \multirow{11}{*}{$10 \%$} & 27575 & 2758 \\
\hline & $\begin{array}{c}\text { General Francisco R. } \\
\text { Murguia }\end{array}$ & & 19944 & 1995 \\
\hline & General Panfilo Natera & & 18850 & 1885 \\
\hline & Jalpa & & 22161 & 2217 \\
\hline & Juan Aldama & & 16911 & 1692 \\
\hline & Miguel Auza & & 17171 & 1718 \\
\hline & Nochistlan De Mejia & & 27574 & 2758 \\
\hline & Sain Alto & & 17487 & 1749 \\
\hline & $\begin{array}{c}\text { Tlaltenango De Sanchez } \\
\text { Roman }\end{array}$ & & 21577 & 2158 \\
\hline & Villa De Cos & & 25781 & 2579 \\
\hline & Villanueva & & 29321 & 2933 \\
\hline \multirow{3}{*}{$\begin{array}{c}\text { En } \\
\text { municipios } \\
\text { con una } \\
\text { población } \\
\text { de } 30001 \\
\text { hasta } 50000 \\
\text { electores } \\
\end{array}$} & Loreto & \multirow{3}{*}{$8 \%$} & 32995 & 2640 \\
\hline & Ojocaliente & & 30892 & 2472 \\
\hline & Valparaiso & & 31936 & 2555 \\
\hline \multirow{7}{*}{$\begin{array}{l}\text { En } \\
\text { municipios } \\
\text { de } 50001 \\
\text { electores en } \\
\text { adelante }\end{array}$} & Fresnillo & \multirow{7}{*}{$5 \%$} & 162488 & 8125 \\
\hline & Guadalupe & & 108405 & 5421 \\
\hline & Jerez & & 54428 & 2722 \\
\hline & Pinos & & 50777 & 2539 \\
\hline & Río Grande & & 52412 & 2621 \\
\hline & Sombrerete & & 51701 & 2586 \\
\hline & Zacatecas & & 106654 & 5333 \\
\hline
\end{tabular}

Evidentemente, estos porcentajes de apoyo ciudadano, resultan excesivos; sin embargo, ni la Suprema Corte de Justicia de la Nación, ni la Sala Superior del TEPJF los declararon inconstitucionales.

Las relaciones de apoyo ciudadano se presentaron al Instituto Electoral del Estado de Zacatecas (IEEZ) en el Formato RAC CI incluido en el Reglamento, lo que permitió que la información se consolidara de manera ordenada y con los requisitos establecidos por la propia Ley Electoral del Estado de Zacatecas y el Reglamento de Candidaturas Independientes. 
Esta revista forma parte del acervo de la Biblioteca Jurídica Virtual del Instituto de Investigaciones Jurídicas de la UNAM

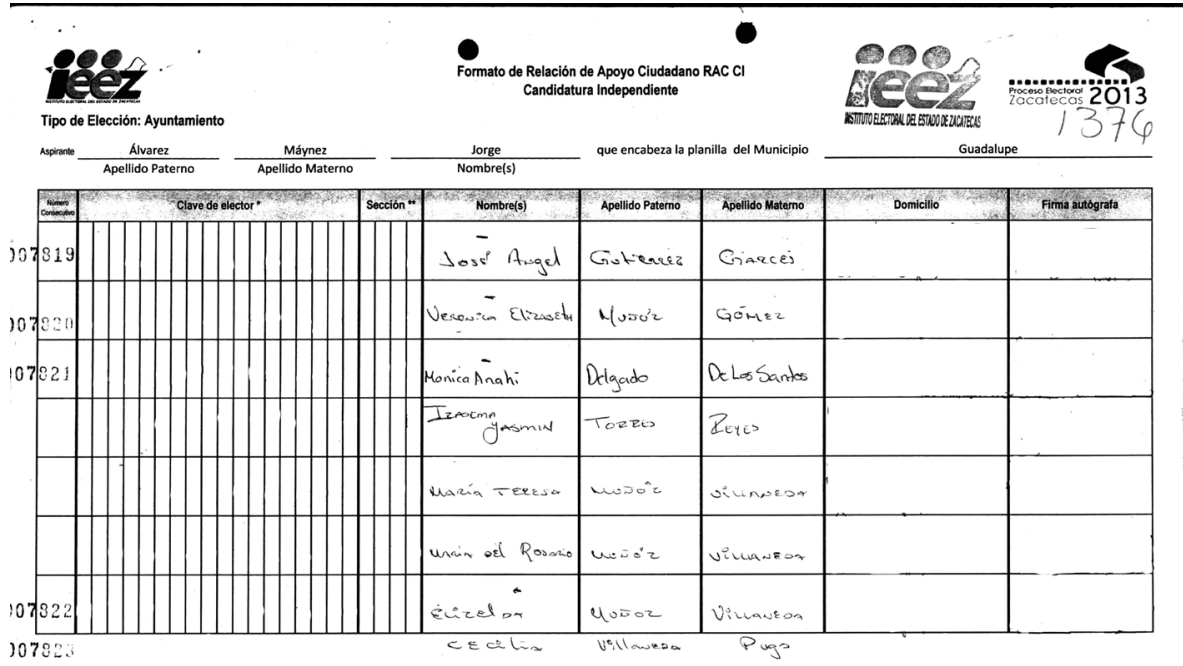

* Anota la clave de elector que aparece en la credencial para votar; está conformada por 18 caracteres (letras y números).

** Escribe el número de sección; cópialo de la credencial, está compuesto por cuatro digitos.

Para regular la etapa de adhesión de apoyo ciudadano, el órgano superior de dirección aprobó los Lineamientos que deberían observar quienes aspiren a una candidatura independiente sobre propaganda para la obtención del apoyo ciudadano, cuyo objeto fue: "Regular la propaganda de los aspirantes a una candidatura independiente para la obtención del apoyo ciudadano".

Dicha propaganda debería contener la identificación plena del aspirante que la difundiera o la hiciera circular, señalar de manera expresa que era una actividad tendiente a la obtención de apoyo ciudadano; así como insertar de manera visible la leyenda: "Aspirante a la candidatura independiente". De igual manera, debería orientar a la ciudadanía de la forma o lugares disponibles para otorgar el apoyo ciudadano.

Se resalta que en el Modelo Zacatecas, no existió intervención ni de la autoridad electoral, ni de notario u otro fedatario, por lo que la experiencia fue que cada candidato tenía sus promotores que se instalaban en plazas, jardines o realizaban visitas domiciliarias a fin de ob-

${ }^{6}$ Formato de apoyo ciudadano presentado por el aspirante a candidato independiente al municipio de Guadalupe, C. Jorge Álvarez Máynez 
Esta revista forma parte del acervo de la Biblioteca Jurídica Virtual del Instituto de Investigaciones Jurídicas de la UNAM

tener la copia de la credencial de elector, llenar el formato y estampar la firma del ciudadano en el formato.

De igual manera, es importante destacar que el periodo de búsqueda de la obtención del voto fue amplio, a diferencia del modelo Quintana Roo, ya que en nuestro caso transcurrió desde la convocatoria y hasta la fecha de entrega del Registro Preliminar, es decir, cincuenta días.

Otra cuestión fundamental: en el modelo Zacatecas, fue que el apoyo ciudadano se otorgó a "Quien encabeza la planilla o fórmula"; de esta manera se personaliza el apoyo ciudadano a un solo ciudadano, quien al obtener el apoyo podrá integrar su planilla o fórmula de la manera que decida.

Esta decisión se tomó al reflexionar qué sucede si el apoyo es para una planilla completa: ¿se podrá sustituir la candidatura propietaria a la Presidencia o la Diputación? Si renuncia parte de la planilla ¿continúa existiendo el vínculo entre el apoyo ciudadano y la candidatura? Al no existir una estructura orgánica con la representación de la candidatura ¿quién puede hacer las sustituciones de candidaturas? ¿Quién tiene la facultad de nombrar representantes de la candidatura? Ante la falta de reglamentación y la evidente "personalización" de la candidatura en el contenido de la Ley Electoral, se determinó otorgar todas estas facultades al candidato o candidata independiente.

La fecha límite para presentar la relación de apoyo ciudadano fue el 6 de abril de 2013. Así los CC. Raúl de Luna Tovar, Israel Espinosa Jaime, César Gerardo González Zavala, Florentino Gómez Lara, Rogelio Cárdenas Hernández, Gerardo Carrillo Nava, Rigoberto López Martínez, Víctor Manuel Guerrero Cruz, Miguel Morales García y Jorge Álvarez Máynez, las presentaron para las elecciones municipales en las siguientes fechas:

\section{Fechas de presentación de las relaciones de apoyo ciudadano}

\begin{tabular}{|c|c|c|c|}
\hline Número & Nombre & Municipio & $\begin{array}{c}\text { Fecha de } \\
\text { Presentación }\end{array}$ \\
\hline 1 & C. Raúl de Luna Tovar & General Enrique Estrada & 25 de marzo \\
\hline 2 & Israel Espinosa Jaime & Sombrerete & 3 de abril \\
\hline 3 & César Gerardo González Zavala & Villa de Cos & 5 de abril \\
\hline 4 & Florentino Gómez Lara & Pinos & 5 de abril \\
\hline 5 & Rogelio Cárdenas Hernández & Zacatecas & 6 de abril \\
\hline 6 & Gerardo Carrillo Nava & Cañitas de Felipe Pescador & 6 de abril \\
\hline 7 & Rigoberto López Martínez & Mazapil & 6 de abril \\
\hline 8 & Víctor Manuel Guerrero Cruz & Villa García & 6 de abril \\
\hline 9 & Miguel Morales García & Sombrerete & 6 de abril \\
\hline 10 & Jorge Álvarez Máynez & Guadalupe & 6 de abril \\
\hline
\end{tabular}


El trabajo jurídico-operativo que desplegó el IEEZ, a través de la Dirección Ejecutiva de Asuntos Jurídicos, tuvo como resultado la revisión, captura y validación de 32732 registros de apoyo ciudadano, en un plazo de cinco días.

\section{Registro preliminar}

Para lograr el registro preliminar además de las firmas requeridas los aspirantes a la candidatura independiente cumplieron con los siguientes requisitos:

a) La presentación de la solicitud de registro de la candidatura independiente, en términos de lo establecido en el artículo 18, fracción I, de la Ley Electoral.

b) Una copia simple y legible de las credenciales de elector de las ciudadanas y los ciudadanos que respaldaron la candidatura independiente.

c) La relación de los integrantes de su comité de campaña electoral, en la que se precisaron las funciones de cada uno.

d) El domicilio oficial del comité de campaña en la capital del estado, sede de distrito o cabecera municipal, según correspondiera.

e) El emblema y los colores con los que pretendía contender, que no deberían ser análogos a los de los partidos políticos con registro o acreditación ante el Instituto, ni contener la imagen o la silueta del candidato.

f) Presentaron su plataforma electoral, la cual debería contener las principales propuestas que sostendría en la campaña electoral.

g) Designaron al tesorero de la candidatura independiente.

h) Señalaron el número y los datos de identificación de la cuenta bancaria aperturada en el estado de Zacatecas para el manejo de los recursos de la candidatura independiente.

i) El informe relativo al monto de los recursos que pretendía gastar en la campaña electoral y el origen de estos.

j) Domicilio para oír y recibir notificaciones.

k) Nombre del representante legal para oír y recibir notificaciones.

A efecto de verificar si quienes dieron su apoyo al candidato independiente aparecían en el padrón electoral con corte al 31 de diciembre de 
Esta revista forma parte del acervo de la Biblioteca Jurídica Virtual del Instituto de Investigaciones Jurídicas de la UNAM

2012, el IEEZ y el Instituto Federal Electoral firmaron una addenda de colaboración al Anexo Técnico número siete al Convenio de Apoyo y Colaboración en Materia de Registro Federal de Electores.

El procedimiento para la verificación de la relación de apoyo ciudadano fue el siguiente: ${ }^{7}$

a) El IEEZ, remitía en medio magnético la base de datos sistematizada del listado de las personas incluidas en la relación de apoyo ciudadano, la cual contenía:

- Número consecutivo.

- Clave de elector.

- Sección electoral.

- Nombre(s), apellido paterno, apellido materno.

- Domicilio completo.

b) El Instituto Federal Electoral a través del Registro Federal de Electores verificaba que quienes aparecieran en la relación de apoyo ciudadano estuvieran en el padrón electoral con corte al 31 de diciembre de 2012.

c) El Instituto Federal Electoral elaboraba el informe del resultado de la verificación y lo remitía al Instituto Electoral del Estado de Zacatecas.

De esta manera la autoridad electoral federal informó al IEEZ, si el apoyo ciudadano al candidato independiente aparecía en el padrón electoral con corte al 31 de diciembre de $2012 .{ }^{8}$

7 Addenda al Anexo Técnico Número Siete al Convenio de Apoyo y Colaboración en Materia del Registro Federal de Electores, que celebraron el Instituto Federal Electoral y el Instituto Electoral del Estado de Zacatecas, en relación con el uso de los instrumentos y productos técnicos que aportó la Dirección Ejecutiva del Registro Federal de Electores para el Proceso Electoral 2013 en el Estado de Zacatecas.

8 Artículo 18, numeral 1, fracción II de la Ley Electoral del Estado de Zacatecas. 
Esta revista forma parte del acervo de la Biblioteca Jurídica Virtual del Instituto de Investigaciones Jurídicas de la UNAM

7. Ejemplo de concentrado del informe de resultados remitido por el Instituto Federal Electoral ${ }^{9}$

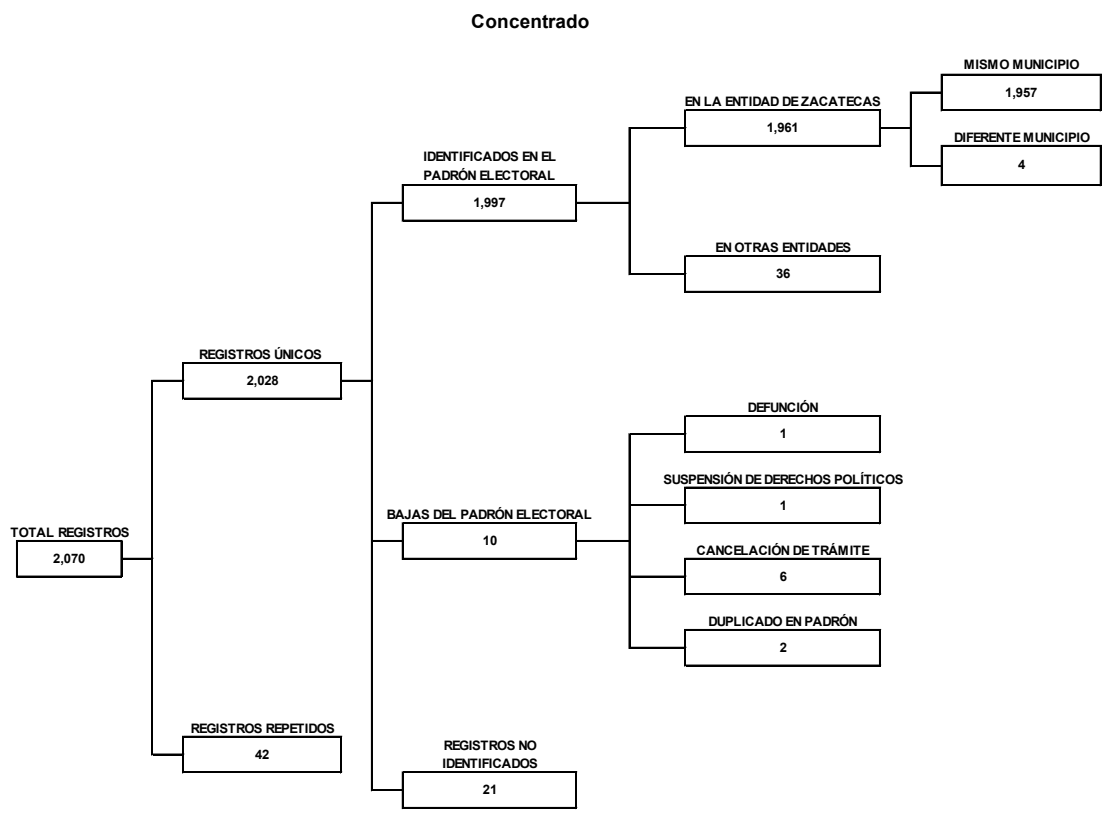

Finalmente el Consejo General del IEEZ aprobó el registro preliminar de nueve aspirantes a la candidatura independiente y les expidió la constancia respectiva. Mención especial merece el hecho de que la Ley Orgánica del Instituto Electoral estableció la competencia de la Comisión de Asuntos Jurídicos para resolver cualquier asunto relacionado con el registro de las candidaturas independientes.

Es de subrayar que el modelo de candidaturas independientes en Zacatecas no limita a quienes hayan obtenido su registro preliminar para que en el periodo registro de candidaturas sean registrados por un partido político.

En la práctica, un ciudadano obtuvo su constancia de registro preliminar y con posterioridad renunció a la candidatura independiente para postularse como candidato a regidor por un partido político, en

9 Resolución RCG-IEEZ-016/IV/2013 que formula el Consejo General con base en el procedimiento de revisión realizado por la Comisión de Asuntos Jurídicos respecto de la procedencia del registro preliminar del C. Víctor Manuel Guerrero Cruz, aspirante a la candidatura independiente al cargo de presidente municipal para el Ayuntamiento de Villa García, Zacatecas, en el proceso electoral de 2013. 
este sentido la interrogante sería: ¿qué destino tuvieron las firmas de apoyo ciudadano?

\section{Registro de candidaturas}

Del 16 al 30 de abril de 2013, inició el registro de candidaturas tanto para los partidos políticos como para los aspirantes a la candidatura independiente.

El aspirante a la candidatura independiente que encabezó la planilla debió presentar su registro ante los Consejos Municipales Electorales correspondientes y de manera supletoria ante el Consejo General del Instituto Electoral del Estado de Zacatecas.

Dos aspirantes presentaron su solicitud de registro ante los Consejos Municipales y siete ante el Consejo General del Instituto Electoral.

Es de destacarse que en la integración de la totalidad de las planillas de los candidatos independientes para ayuntamientos se cumplió con las disposiciones referentes a la cuota de género que se contemplan en los Lineamientos para el registro de candidaturas a cargos de elección popular de los partidos políticos y coaliciones, lo que permitió que las planillas se conformaran de manera paritaria.

\section{Campañas electorales}

Con la aprobación del registro de candidaturas iniciaron las campañas electorales de los nueve candidatos independientes, la Coalición "Alianza Rescatemos Zacatecas" y las candidaturas de los partidos políticos.

En la capital del estado, se celebró un debate entre los aspirantes a la Presidencia Municipal, en este ejercicio, desde luego, se incluyó al candidato independiente. 
Esta revista forma parte del acervo de la Biblioteca Jurídica Virtual del Instituto de Investigaciones Jurídicas de la UNAM del Ayuntamiento de Zacatecas
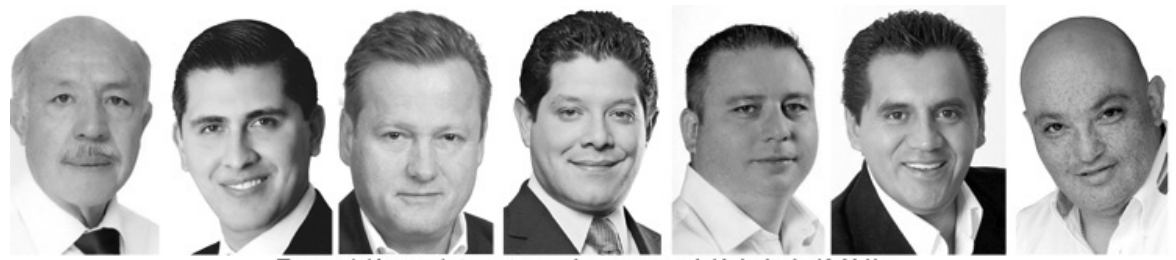

Transmisión por internet: www.ieez.org.mx / 16 de Junio 18:00 Hrs.

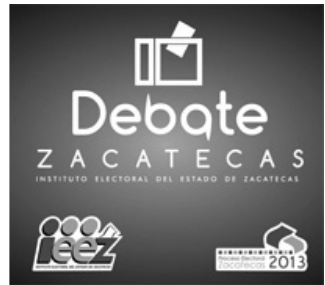

\section{Acceso a radio y televisión}

Como se ha señalado, el Reglamento de Candidaturas Independientes incluyó las disposiciones necesarias para armonizar el proceso electoral al ingreso de las candidaturas independientes, por tanto, reconoce el derecho de los candidatos independientes para acceder a radio y televisión.

En dicho ordenamiento se estableció que a los candidatos independientes, en conjunto, les correspondería un tiempo igual en radio y televisión al que correspondería a un partido político de nuevo registro.

Mención especial merece que los candidatos independientes tuvieron acceso a la radio y televisión al inicio de las campañas en igualdad de condiciones de los partidos políticos, en virtud a que el Instituto Electoral del Estado puso a disposición del Instituto Federal Electoral la parte correspondiente del tiempo asignado a la autoridad electoral para que se asignara a los candidatos independientes. Es importante reconocer que el IFE no impugnó tal disposición reglamentaria y, por el contrario, apoyó a la autoridad local para encontrar las mejores condiciones para el acceso a este derecho.

Para lograrlo se sostuvieron diversas reuniones con el presidente del Comité de Radio y Televisión del IFE y los consejeros y consejeras del IEEZ, con la finalidad de dar a conocer a los candidatos in- 
Esta revista forma parte del acervo de la Biblioteca Jurídica Virtual del Instituto de Investigaciones Jurídicas de la UNAM

dependientes lo relativo a los criterios concernientes al acceso a radio y televisión.

El Consejo General del Instituto Federal Electoral emitió un Acuerdo por el que se aprobaron las bases para el acceso a radio y televisión para las campañas en las entidades federativas que contemplen la figura de las candidaturas independientes. ${ }^{10}$

Con base en el referido Acuerdo, el Consejo General del Instituto Electoral del Estado de Zacatecas, emitió un Acuerdo por el que se aprobó el Modelo de Distribución del Tiempo en Radio y Televisión para la propuesta de pauta de los Candidatos Independientes que se presentó al Comité de Radio y Televisión del Instituto Federal Electoral para el acceso a radio y televisión durante las campañas electorales. ${ }^{11}$

En este modelo de pauta se estableció el número de impactos a que tendrían derecho los candidatos independientes, en su conjunto, a un tiempo igual en radio y televisión al que correspondería a un partido político de nuevo registro.

En contra del Acuerdo del Consejo General del Instituto Federal Electoral por el que modificó el Acuerdo identificado con el número JGE44/2013, con motivo de la propuesta del modelo de distribución del tiempo en radio y televisión para los candidatos independientes durante las campañas, en el proceso electoral ordinario 2013, se interpuso el Recurso de Apelación SUP-RAP-53/2013.

La Sala Superior del Tribunal Electoral del Poder Judicial de la Federación determinó modificar el Acuerdo de la Junta General Ejecutiva del IFE y ordenó al Comité de Radio y Televisión que se pronunciara sobre el pautado de los candidatos independientes del Estado de Zacatecas.

El Comité de Radio y Televisión del IFE en cumplimiento a la sentencia emitió el Acuerdo ACRT/30/2013.

10 Acuerdo CG93/2013 del Consejo General del Instituto Federal Electoral por el que se aprueban las bases para el Acceso a Radio y Televisión para las campañas en las entidades federativas que contemplen la figura de las candidaturas independientes.

11 Acuerdo ACG-IEEZ-47/IV/2013 del Consejo General del Instituto Electoral del Estado de Zacatecas, por el que se aprueba el Modelo de Distribución del Tiempo en Radio y Televisión para la propuesta de pauta de los candidatos independientes que será presentado al Comité de Radio y Televisión del Instituto Federal Electoral para el acceso a radio y televisión durante las campañas en el proceso electoral ordinario de 2013. 
En este Acuerdo se estableció el número de impactos a que tendrán derecho los candidatos independientes, en su conjunto, a un tiempo igual en radio y televisión al que correspondería a un partido político de nuevo registro, que en esta ocasión se tradujo en 106 impactos de 30 segundos en cada emisora de radio y canal de televisión.

Además, para que los candidatos independientes tuvieran certeza respecto al procedimiento de acceso a los tiempos en radio y televisión, los requerimientos técnicos de los materiales audiovisuales, plazos para la entrega de materiales, entre otros aspectos técnicos, la Comisión de Comunicación Social aprobó el Manual Operativo para el Acceso a Radio y Televisión de Candidatos independientes.

Asimismo, los candidatos independientes utilizaron las redes sociales (Facebook, Twitter, etcétera) como una estrategia de promoción de los eventos realizados en su campaña electoral.

\section{Boleta y documentación electoral}

El Instituto Electoral garantizó que los emblemas y colores de los candidatos independientes no fueran análogos a los de los partidos políticos con acreditación ante el Instituto; asimismo verificó que no contuvieran la imagen o la silueta del candidato y que estuvieran exentos de alusiones raciales y/o religiosas.

9. Boleta electoral para la elección del ayuntamiento del municipio de Sombrerete, Zacatecas

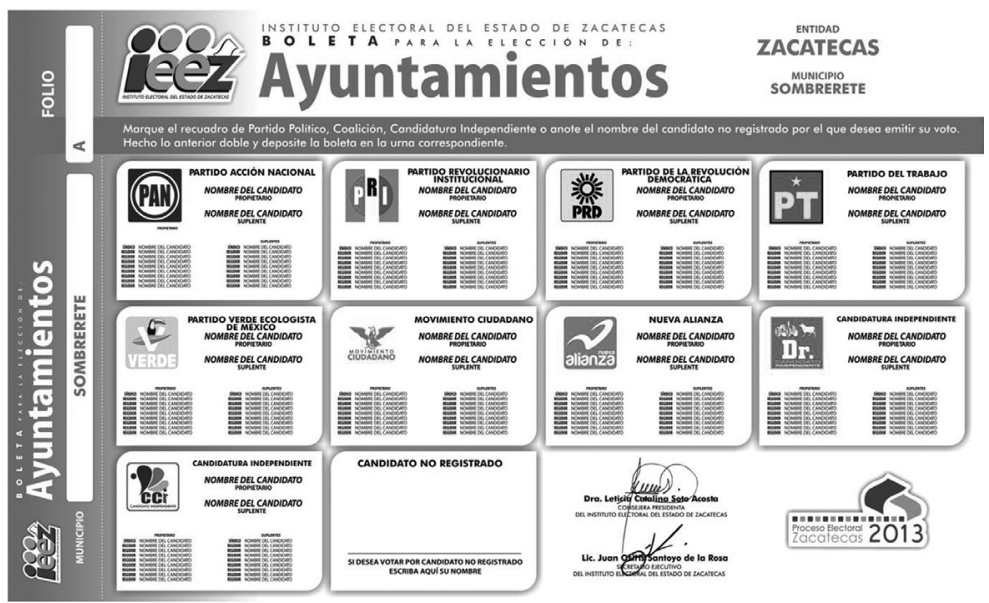


De igual manera, en la documentación electoral se contemplaron los espacios relativos a los emblemas de los candidatos independientes en los municipios correspondientes.

\section{Listado Nominal de Electores}

El Reglamento de Candidaturas Independientes, reconoce el derecho de los candidatos independientes de recibir el listado nominal de electores.

Conforme a lo señalado en la Addenda al Anexo Técnico Número Siete al Convenio de Apoyo y Colaboración en Materia del Registro Federal de Electores y con la finalidad de guardar la confidencialidad de los datos personales contenidos en el listado nominal de electores se estableció que éste se entregaría de manera exclusiva al representante del candidato independiente el día de la jornada electoral.

Inconforme con la entrega del listado hasta el día de la jornada electoral, un candidato independiente promovió Juicio para la Protección de los Derechos Político-Electorales del Ciudadano ante la Sala Regional del Tribunal Electoral del Poder Judicial de la Federación, correspondiente a la Segunda Circunscripción Plurinominal.

Al respecto, el Instituto Electoral del Estado solicitó que la Sala Superior del Tribunal Electoral del Poder Judicial de la Federación, ejerciera la facultad de atracción y al resolver el expediente SUPJDC-976/2013, confirmó el acto impugnado, es decir, la entrega de la lista nominal de electores a los candidatos independientes hasta el día de la jornada electoral.

\section{Conclusiones}

Es necesario que en la Constitución Política de los Estados Unidos Mexicanos y en una ley general se establezcan las bases mínimas del modelo de candidaturas independientes con la finalidad de que en la legislación secundaria se fijen reglas y requisitos viables para la participación de la ciudadanía por medio de las candidaturas independientes en cada una de las entidades federativas, estas bases deberán instrumentarse apoyadas en las convenciones internacionales. 
Las bases que se establezcan en la Constitución federal y en la ley general, deberán tener en consideración, entre otros, los siguientes aspectos:

- Acceso de los candidatos independientes a radio y televisión, en condiciones de equidad (tiempo aire que corresponda a los partidos políticos de nueva creación).

- Obligación de respetar las reglas de paridad o equidad entre los géneros y otras acciones afirmativas a favor de las mujeres.

- Debates que permitan contrastar la ideología y las plataformas electorales.

- Sistema de obtención del apoyo ciudadano.

- Empatar los tiempos de precampaña con los tiempos para la obtención del apoyo ciudadano (para evitar el transfuguismo).

- Señalar quiénes tienen la personería para interponer medios de impugnación ante las autoridades electorales (candidatos independientes y representantes legales).

- Que los candidatos independientes tengan derecho de acceder a los cargos de elección popular por el principio de representación proporcional.

- Definir el modelo de financiamiento (público, privado o mixto).

- Adecuar el modelo de fiscalización para los candidatos independientes (en virtud a que no pueden aplicarse las mismas reglas que a los partidos políticos, ya que los candidatos independientes no cuentan con estructuras profesionales en materia de contabilidad, como sí la tienen los partidos políticos).

En suma, deben establecerse reglas que generen equidad sin que se produzca un fenómeno contrario de inequidad hacia el sistema de partidos políticos. Sin duda, la experiencia Zacatecas ha contribuido a bordar el andamiaje jurídico que debe tomarse como una referencia en la construcción del modelo federal y de las entidades federativas.

\section{Fuentes consultadas}

Sentencia de la Acción de Inconstitucionalidad 57/2012 y sus acumuladas 58/2012, 59/2012 y 60/2012, emitida por la Suprema Corte 
Esta revista forma parte del acervo de la Biblioteca Jurídica Virtual del Instituto de Investigaciones Jurídicas de la UNAM

de Justicia de la Nación el 10 de diciembre de 2012, promovidas por la Procuradora General de la República y los Partidos Políticos Movimiento Ciudadano, del Trabajo y de la Revolución Democrática, en contra de los Poderes Legislativo y Ejecutivo del Estado de Zacatecas.

Sentencia del Juicio para la Protección de los Derechos Político Electorales del Ciudadano SUP-JDC-41/2013 y acumulados emitida por la Sala Superior del Tribunal Electoral del Poder Judicial de la Federación el siete de febrero de dos mil trece.

Acuerdo ACG-IEEZ-090/IV/2013 del Consejo General del Instituto Electoral del Estado de Zacatecas, por el que se aprueba el cómputo estatal de la elección de Regidores por el principio de representación proporcional, se declara su validez y se asignan a los partidos políticos: Acción Nacional, Revolucionario Institucional, de la Revolución Democrática, del Trabajo, Verde Ecologista de México, Movimiento Ciudadano y Nueva Alianza, las regidurías que por este principio les corresponden de acuerdo a la votación obtenida por cada uno de ellos, en el proceso electoral del año dos mil trece y se expiden las constancias de asignación respectivas.

Acuerdo ACG-IEEZ-025/IV/2013 del Consejo General por el que se aprueba la modificación, en su parte conducente, de la Convocatoria dirigida a las ciudadanas y a los ciudadanos que de manera independiente deseen participar en la elección ordinaria para renovar los Ayuntamientos de los 58 Municipios del Estado de Zacatecas, por el principio de mayoría relativa, para el periodo constitucional 2013-2016 y de la Convocatoria dirigida a las ciudadanas y a los ciudadanos que de manera independiente deseen participar en la elección ordinaria para renovar la Honorable Legislatura del Estado de Zacatecas, para el periodo constitucional 2013-2016; con base en la sentencia dictada por la Sala Superior del Tribunal Electoral del Poder Judicial de la Federación, en el expediente SUP-JDC-41-2013 y acumulados.

Formato de apoyo ciudadano presentado por el aspirante a candidato independiente al municipio de Guadalupe, C. Jorge Álvarez Máynez.

Addenda al Anexo Técnico Número Siete al Convenio de Apoyo y Colaboración en Materia del Registro Federal de Electores, que celebraron el Instituto Federal Electoral y el Instituto Electoral del Estado de Zacatecas, en relación con el uso de los instrumentos y 
productos técnicos que aportó la Dirección Ejecutiva del Registro Federal de Electores para el Proceso Electoral 2013 en el Estado de Zacatecas.

Resolución RCG-IEEZ-016/IV/2013 que formula el Consejo General con base en el procedimiento de revisión realizado por la Comisión de Asuntos Jurídicos respecto de la procedencia del registro preliminar del C. Víctor Manuel Guerrero Cruz, aspirante a la candidatura independiente al cargo de Presidente Municipal para el Ayuntamiento de Villa García, Zacatecas, en el proceso electoral dos mil trece.

Acuerdo CG93/2013 del Consejo General del Instituto Federal Electoral por el que se aprueban las bases para el Acceso a Radio y Televisión para las campañas en las entidades federativas que contemplen la figura de las Candidaturas Independientes.

Resolución recaída en el Recurso de Apelación SUP-RAP-53/2013 del ocho de mayo de dos mil trece emitida por la Sala Superior del Tribunal Electoral del Poder Judicial de la Federación.

Acuerdo ACG-IEEZ-47/IV/2013 del Consejo General del Instituto Electoral del Estado de Zacatecas, por el que se aprueba el Modelo de Distribución del Tiempo en Radio y Televisión para la propuesta de pauta de los Candidatos Independientes que será presentado al Comité de Radio y Televisión del Instituto Federal Electoral para el acceso a radio y televisión durante las campañas en el proceso electoral ordinario dos mil trece.

Resolución RCG-IEEZ-016/IV/2013 que formula el Consejo General con base en el procedimiento de revisión realizado por la Comisión de Asuntos Jurídicos respecto de la procedencia del registro preliminar del C. Víctor Manuel Guerrero Cruz, aspirante a la candidatura independiente al cargo de Presidente Municipal para el Ayuntamiento de Villa García, Zacatecas, en el proceso electoral dos mil trece.

Acuerdo CG93/2013 del Consejo General del Instituto Federal Electoral por el que se aprueban las bases para el Acceso a Radio y Televisión para las campañas en las entidades federativas que contemplen la figura de las Candidaturas Independientes.

Resolución recaída en el Recurso de Apelación SUP-RAP-53/2013 del ocho de mayo de dos mil trece emitida por la Sala Superior del Tribunal Electoral del Poder Judicial de la Federación. 
Acuerdo ACG-IEEZ-47/IV/2013 del Consejo General del Instituto Electoral del Estado de Zacatecas, por el que se aprueba el Modelo de Distribución del Tiempo en Radio y Televisión para la propuesta de pauta de los Candidatos Independientes que será presentado al Comité de Radio y Televisión del Instituto Federal Electoral para el acceso a radio y televisión durante las campañas en el proceso electoral ordinario dos mil trece.

Ley Electoral del Estado de Zacatecas.

Ley Orgánica del Instituto Electoral del Estado de Zacatecas.

Reglamento de Candidaturas Independientes del Estado de Zacatecas.

Página web del Instituto Electoral del Estado de Zacatecas: $w w w . i e e z$. org.mx. 